\title{
TOTAL QUALITY MANAJEMEN DAN DAYA SAING \\ PERUSAHAAN SEBAGAI ANTESENDEN KEPUASAN \\ PELANGGAN MENGHADAPI PERDAGANGAN BEBAS
}

CAFTA 2010

\author{
Harianto Respati \\ Fakultas Ekonomi Jurusan Manajemen Universitas Merdeka Malang \\ Jl. Terusan Raya Dieng 62-64 Malang \\ E-mail : patidarma@yahoo.com
}

\begin{abstract}
Manufacturers in Indonesia face new challenge related to prevailing free trade of CAFTA 2010 especially for imported products from Cina. This phenomenon provides a gab for further researchs to have a qualtitative research study on operational management which related to the implementation of Total Quality Management, competitive ability and customer satisfaction. This journal presents the phenomenon of prevailing free trade of CAFTA and some concepts, as well as measurement for TQM variables, Competitive ability of the company and customer satisfaction. Objective of this journal is expected to be able to assist the next researchers who want to conduct a research study on operational management, especially that concern to TQM, competitive ability of the company and customer satisfaction.
\end{abstract}

\section{Keywords : CAFTA, TQM, keunggulan kompetitif, kepuasan pelanggan}

Menghadapi persaingan bebas 2003 pada awal era globalisasi bagi negara-negara ASEAN memberikan dampak pada perkembangan dunia usaha dan persaingan yang ketat, semua pelaku bisnis dituntut untuk lebih kreatif dan kompetitif. Globalisasi diyakini akan menyediakan peluang dan sejumlah tantangan bagi perusahaan jasa maupun manufaktur. Tantangannya yakni pelanggan/pembeli bebas menentukan pilihan dengan tidak memandang asal produk dari negara mana namun lebih pada orientasi kualitas dan harga yang 
terjangkau. Pada kondisi seperti ini, hanya produk-produk yang berkualitas akan memenangkan persaingan dan mempertahankan posisinya dipasar. Oleh karena itu, manufaktur dituntut untuk menciptakan dan meningkatkan strategi dan prosedur yang tepat untuk menjamin pencapaian sasaran produk berkualitas dengan harga yang terjangkau. Kualitas produk yang sesuai dengan harapan konsumen akan memberikan keuntungan perusahaan walaupun penetapan harga produk diatas harga rata-rata pasar yang pada akhirnya akan meningkatkan total penjualan perusahaan.

Perdagangan bebas CAFTA. Menghadapi perdangan bebas AFTA 2010 yang sudah diratifikasi sejak 2004 dan diimplementasikan dengan penurunan bea masuk secara gradual hingga tahun 2008 tinggal 5\% dan tahun 2010 menjadi $0 \%$. Banyak kalangan industri di Indonesia menyatakan siap dan ada pula yang belum siap menghadapi perdagangan bebas CAFTA ini. Kenyataan yang terjadi bahwa pemerintah baru mensosialisasikan perdagangan bebas CAFTA sekitar 6 bulan sebelum pemberlakuan CAFTA, yang seharusnya pemerintah wajib mensosialisasikan perdagangan bebas CAFTA semenjak dilakukan ratifikasi pada tahun 2004 lalu dan memberikan semacam early warning secara terus-menerus sehingga industri kecil maupun besar Indonesia siap menyongsong perdagangan bebas CAFTA.

Peluang perdagangan bebas CAFTA. Pemberlakuan perdangangan bebas CAFTA 2010 harus dilihat sebagai satu peluang untuk melakukan langkah-langkah ekspansi ke kawasan Asia Tenggara dan Cina. Perusahaan perlu mengotimalkan atau meningkatkan potensi sumber-sumber yang tersedia. Terbukanya perdagangan bebas ini, memberikan kesempatan untuk melakukan kerjasama antara pengusaha Indonesia dan Cina untuk menghasilkan produk berkualitas dengan harga terjangkau dengan mempertimbangkan masing-masing kekuatan dan kelemahan terhadap sumber-sumber perusahaan. Dengan demikian praktek usaha yang tidak sehat seperti strategi dumping dapat dihindari. 
Riwayat CAFTA. Perdagangan bebas di wilayah Asia Tenggara telah diusulkan sejak tahun 1992. Pelaksanaan perdagangan bebas untuk kawasan ASEAN (persatuan negara-negara di wilayah Asia Tenggara) dimulai tahun 2003. AFTA (ASEAN Free Trade Area) merupakan kesepakan diantara negaranegara Asia Tenggara untuk melakukan perdagangan tanpa dipungut bea masuk. Pada mulanya anggota AFTA hanya terdiri dari lima negara, kini sudah bertambah menjadi 10 negara. AFTA pada awalnya disepakati untuk diberlakukan pada tahun 2008 kemudian diajukan menjadi 2003. Tujuan AFTA diantaranya untuk meningkatkan kesejahteraan negara-negara anggota.

Pesatnya perdagangan di wilayah Asia Tenggara menjadikan Cina mulai tertarik untuk berdagang dengan negara ASEAN. Sebagai konsekuensi ketertarikannya, maka Cina mendonasikan uang sebesar US \$5 juta kepada ASEAN-China Coperation Fund pada pertemuan puncak ASEAN Summit ke10 di Vientiane, Laos pada tahun 2004. Kemudian pada ASEAN-China Summit ke-12 di Hua Hin, Thailand, ASEAN menerima kehadiran Cina melalui penandatanganan CAFTA di Bangkok pada tanggal 15 Agustus 2009. Pemberlakuan Cina-ASEAN Free Trade Area (CAFTA) pada tanggal 1 Januari 2010. Pemberlakuan ini menjadikan kawasan Asia Tenggara menjadi sebuah wilayah ekonomi baru, persaingan makin ketat dan segala sesuatu menjadi more borderless. Cina merupakan negara yang memiliki perekonomian terbesar di dunia. Kehadiran Cina di wilayah Asia Tenggara akan menjadi momok yang begitu menakutkan karena produk manufakturnya yang menggerogoti seluruh pasar dunia, termasuk Indonesia. Harga barang-barang Cina sangat kompetitif bahkan jauh dibawah harga produk hasil Indonesia.

Kesiapan industri manufaktur Indonesia. Pada tataran ASEAN, Manufaktur Indonesia masih dapat mengimbangi arus persaingan. Dari 10 negara ASEAN, Indonesia menempati peringkat keempat untuk ekspor dan impor sehingga dari sisi persaingan, Indonesia masih cukup disegani. Indonesia memiliki populasi sebesar 228.523.000 jiwa, hampir setengah dari 
populasi sembilan negara ASEAN. PDB Indonesia sekitar Rp. 4.131 triliun dengan 60\%-nya ditopang oleh konsumsi swasta. Ekspor Indonesia hanya kurang dari 30\% PDB. Indonesia merupakan negara yang pertumbuhan ekonominya ditopang oleh konsumsi. Dari sisi ekspor, Indonesia mengandalkan primary product seperti batu-bara, CPO dan minyak bumi. Sebagai negara yang konsumtif, seharusnya industri barang / manufaktur tumbuh dengan pesat, namun justru sebaliknya industri di Indonesia hanya fokus pada produk primer tanpa memikirkan sektor sekunder (Prasetyantoko, Warta Ekonomi, 2010).

Jika melihat persoalan secara cermat, Indonesia tergolong siap untuk berkompetisi dengan negara-negara ASEAN, terbukti dari perbandingan nilai ekspor lebih besar dari pada nilai impor dari tahun 2001 hingga 2008. Demikian pula nilai eksport dari tahun 2001 hingga 2008 mengalami kenaikan secara terus-menerus. Namun kenyataannya bahwa produk Cina memiliki nilai kompetitif yang tinggi yakni penawaran lebih murah dari produk manufaktur Indonesia, maka akan menciptakan kecemasan bagi industri Indonesia untuk bersaing dengan Cina. Daya saing Indonesia dibanding dengan Cina seperti bumi dan langit. Kondisi infrastruktur, Sumber Daya Manusia, pelaksanaan God Corporate Governance (GCG), penerapan teknologi, struktur perbankan yang hingga kini masih jauh dari ideal untuk menopang perusahaan manufaktur di Indonesia. Permasalahan utama adalah menyangkut high cost economy di tengah berjuta potensi yang ada sehingga melemahkan daya saing Indonesia khususnya daya saing perusahaan. Nampaknya kesiapan Indonesia menghadapi CAFTA masih meragukan.

Dampak perdagangan bebas CAFTA 2010. Meninjau bahwa Cina yang memiliki nilai mata uang yang lemah, cadangan devisa yang besar, efisiensi yang tinggi karena jumlah penduduk lebih besar sehingga upah buruh murah. Jika Indonesia tidak segera berbenah diri maka (1) Pelaku dunia usaha khususnya UKM terancam gulung tikar karena konsumen lebih memilih 
produk impor yang lebih murah, maka pengangguran dan kemiskinan akan meningkat, (2) Dikawatirkan nilai impor lebih besar dari pada nilai ekspor sehingga neraca perdagangan Indonesia menjadi negatif, (3) PDB Indonesia terancam menurun. Fenomena yang akan terjadi ini merupakan tantang bagi industri manufaktur Indonesia untuk ekstra lebih keras memperbaiki manajemen dan kinerja perusahaan.

Peran Total Quality Manajemen. TQM merupakan upaya untuk meningkatkan kinerja perusahaan melalui perbaikan manajemen secara terusmenerus (continuous improvement management) dengan memanfaatkan secara optimal sumber-sumber organisasi yang tersedia untuk menghasilkan produk berkualitas serta kepuasan konsumen dan pelanggan. Singkatnya, TQM lebih dikenal dengan program kerja perusahaan. TQM muncul di Jepang diimplementasikan sebagai program kerja Pemerintah Jepang untuk menghadapi persaingan internasional. Kenyataannya program TQM Jepang berhasil memenangkan persaingan perdagangan dengan negara Amerika Serikat pada tahun 1980an terutama untuk produk otomotif dan elektronik, sehingga banyak industri-industri di negara Amerika Serikat maupun Eropa mempelajari dan menerapkan TQM untuk memajukan industri mereka. Mempelajari fenomena terdahulu, maka pantaslah bagi industri di Indonesia untuk lebih mengintensifkan program kerja TQM atau mendorong industri manufaktur yang ada untuk melakukan program kerja TQM dalam rangka menghadapi persaingan bebas CAFTA 2010. Tentunya program kerja ini harus didukung sepenuhnya oleh Pemerintah, mengingat ketidaksiapan Indonesia menghadapi CAFTA seperti yang dikutip dari Warta Ekonomi (2010), terdapat 10 masalah penyebab Indonesia belum siap menyambut CAFTA 2010 diantaranya (1) Keterbatasan infrastruktur, (2) Peraturan yang belum harmonis, (3) Rendahnya kualitas SDM, (4) Belum sempurnanya implementasi GCG, (5) Perilaku konsumtif masyarakat, (6) Rendahnya daya saing Indonesia, (7) Masih tertinggalnya pembangunan dibidang teknologi informasi dan 
komunikasi, (8) Keterbatasan akses permodalan, (9) Kapasitas produksi, (10) Rendahnya penetrasi produk Indonesia. Diperkirakan sebagian besar perusahaan manufaktur skala besar siap untuk menghadapi CAFTA. Hal ini disebabkan perusahaan manufaktur skala besar baik investasi asing maupun domestik sudah mempersiapkan diri jauh hari sebelumnya untuk menghadapi perdagangan bebas CAFTA.

Daya saing perusahaan. Untuk menghadapi perdagangan bebas CAFTA, salah satu andalan yang dapat dilakukan oleh perusahaan manufaktur yakni meningkatkan kepuasan pelanggan. Kepuasan pelanggan akan memberikan dampak terhadap loyalitas serta perolehan pembeli baru sehingga apabila hal ini terwujud maka perusahaan memperoleh daya saing yang kuat. Daya saing merupakan kemampuan yang dimiliki oleh perusahaan untuk memenangkan persaingan baik pasar domestik maupun global. Douglas (1999) menjelaskan implementasi daya saing perusahaan dibedakan menjadi tiga strategi yakni cost leadership, quality focus dan differentation. Kemampuan daya saing yang baik dan implementasi Total Quality Management yang benar merupakan modal utama bagi perusahaan manufaktur untuk menyongsong persaingan global, CAFTA khususnya.

\section{PEMBAHASAN}

Jurnal ini bertujuan untuk membantu peneliti yang ingin mendalami bidang manajemen operasional khususnya tentang Total Quality Managment (TQM), daya saing perusahaan dan kepuasan pelanggan. Isu dan fenomena tentang kondisi perekonomian di Indonesia pada tahun 2010 seperti perdagangan bebas CAFTA dan persaingan global, memberikan celah bagi peneliti untuk melakukan studi terhadap kesiapan daya saing perusahaan manufaktur nasional dalam menghadapi perdagangan bebas. Selain itu, jurnal ini disajikan untuk memberikan informasi lebih lanjut tentang konsep dan pengukuran untuk TQM, daya saing perusahaan dan kepuasan pelanggan. 


\section{Total Quality Management}

Manajemen Kualitas (Quality Management) atau Manajemen Kualitas Terpadu (Total Quality Management/TQM) didefinisikan sebagai suatu cara meningkatkan performa secara terus menerus (countinous performance improvement) pada setiap level operasi atau proses, dalam setiap area fungsional dari suatu organisasi, dengan menggunakan semua sumber daya manusia dan modal yang tersedia (Gaspersz, 2002). Banyak pengertian yang menjelaskan tentang Total Quality Manajemen, secara sederhana TQM merupakan pendekatan manajemen berorientasi jangka panjang dengan tujuan memperoleh kepuasan pelanggan (Gaspersz, 2002).

Total Quality Management (TQM) muncul pada tertengahan tahun 1980an sebagai respon atas serangan Jepang terhadap pasar AS dengan produk elektronik dan otomotif yang berkualitas tinggi dan murah.TQM didefinisikan sebagai filosofi organisasi yang memerlukan partisipasi seluruh pekerja pada setiap tingkatan untuk lebih fokus pada usaha perbaikan aktivitas bisnis mereka (Mehra et al. 2001). TQM merupakan suatu jalan baru bagi manajemen organisasi untuk meningkatkan kualitas dan kinerja organisasi. Metode pendekatan untuk melakukan praktek TQM dapat berpedoman pada ajaran Philip B Crosby, W. Edward Deming, Armand V. Feigenbaum, Kaoru Ishikawa dan J.M Juran (Gaspersz, 2002, 487). Mehra et al. (2001) mengatakan bahwa TQM merupakan perbaikan secara terus menerus dalam kurun waktu jangka panjang yang memerlukan sumber-sumber signifikan baik keuangan maupun sumberdaya manusia. Pandangan yang sama dikemukakan oleh Bruce et al. (2007) bahwa TQM fokus pada pengembangan organisasi dan tanggap terhadap kepuasan konsumen. TQM membutuhkan partisipasi seluruh anggota organisasi untuk melakukan pengembangan proses, produk, jasa layanan dan pengembangan budaya secara berkelanjutan. Mehra dan Ranangathan (2008) mengatakan bahwa TQM merupakan proses yang dinamis 
bukan statis, merupakan usaha berkelanjutan secara terus menerus tanpa batas waktu ataupun target waktu dan proses TQM tidak dapat dipertimbangkan secara sempurna ketika tidak ada tujuan yang jelas, oleh karenanya TQM sudah menjadi jalan hidup menuju kualitas.

\section{Riwayat singkat TQM}

Penulis bernama Ishikawa (1976) menjelaskan tentang langkah-langkah perbaikan kualitas, kemudian Crosby (1979) mengembangkan temuan Ishikawa dan mendefinisikan 14 langkah untuk melakukan perbaikan kualitas (quality improvement) diantaranya seperti mengutamakan pelatihan, penyelesaian masalah, siklus kualitas sebagai metode untuk mencapai perbaikan berkesinambungan. Deming (1986) pada buku petunjuk kerjanya tentang "Out of the Crisis", membuka rahasia 14 prinsip yang menjadi dasar dari TQM. Kemudian Juran (1986) mengidentifikasi tiga dasar fungsi proses manajemen kualitas yakni planning, organization dan control sebagai langkah tingkatan program perbaikan kualitas. Untuk keberhasilan perbaikan kualitas, Feigenbaum (1991) menekankan pada kebutuhan kepemimpinan, komitmen terhadap kualitas perusahaan dan partisipasi sebagai pekerja. Beberapa saran tentang studi manajemen kualitas diatas telah menjadi dasar filosofi dan saran TQM.

Semenjak dilahirkan, TQM berorientasi pada pelanggan (Mehra dan Ranganathan, 2008). Catatan Goldman (2005) dinyatakan bahwa kebutuhan pelanggan seharusnya dipenuhi dalam bentuk desain dan pengembangan produk dan jasa. Bagaimanapun, permintaan pelanggan seharusnya diperlakukan sebagai rekan kerja untuk pengembangan siklus produk, sehingga tidak mengejutkan bahwa literatur TQM dan marketing memberikan tekanan yang sama terhadap kepuasan pelanggan (Mehra dan Ranganathan, 2008). 


\section{Pengukuran TQM}

Perdebatan dampak TQM dan penelitian tentang TQM meningkat dratis pada tahun 1990an (Fillippini, 1997). Walaupun banyak penelitian tentang TQM, banyak pertanyaan masih belum terjawab misalnya menentukan konstruk TQM (Fillippini, 1997). Penelitian tentang konstruk TQM mempunyai tingkat pertimbangan yang berbeda-beda (Das et al. 2008).

Terziovski (2006) melakukan analisis faktor konfirmatory terhadap TQM sebagai variabel independen beserta dengan pengukurannya, hasil analisis tersebut menghasilkan kelompok variabel bebas seperti variabel Leadership, People Management, Customer focus, Strategic Planning, Information and analysis dan Process Management.

Sila (2006) melakukan tinjauan dari beberapa literatur tentang konstruk TQM. Hasil studi menemukan tujuh kategori pengukuran TQM meliputi leadership, strateggic planning, customer focus, information and analyisis, human resource management (HRM), process management dan supplier management. Dibawah ini Sila Ismali (2006) menyajikan variabel laten yang dapat merefleksikan dimensi TQM beserta indikator dan pengukurannya yang diambil dari beberapa sumber seperti pada tabel dibawah ini:

\section{Tabel 1}

TQM beserta Indikator dan Pengukurannya.

\begin{tabular}{|l|l|}
\hline \multicolumn{1}{|c|}{ Indikator TQM } & \multicolumn{1}{|c|}{ Pengukuran } \\
\hline Leadership & $\begin{array}{l}\text { - Top management and supervisory } \\
\text { commitment leadership. } \\
\end{array}$ \\
& $\begin{array}{l}\text { citizenship } \\
\text { Strategic planning }\end{array}$ \\
& $\begin{array}{l}\text {-Quality mission, goals dan policy } \\
\text {-Strategy desponsibility dan }\end{array}$ \\
\hline Customer focus & -Customer dan market knowledge \\
\hline
\end{tabular}




\begin{tabular}{|c|c|}
\hline & $\begin{array}{l}\text {-Attention to customer satisfaction } \\
\text {-Management of customer } \\
\text { relationship }\end{array}$ \\
\hline $\begin{array}{l}\text { Information dan } \\
\text { Analysis }\end{array}$ & $\begin{array}{l}\text {-Performance measuremet and } \\
\text { analysis } \\
\text {-Information management } \\
\text {-Use of information technology } \\
\text {-Quality tools } \\
\text {-Benchmarking }\end{array}$ \\
\hline $\begin{array}{l}\text { Human resource } \\
\text { Management }\end{array}$ & $\begin{array}{l}\text {-Employee involement } \\
\text {-Employee empowerement } \\
\text {-Teamwork } \\
\text {-Reward } \\
\text {-Recognition dan performance } \\
\text { appraisal } \\
\text {-employee training }\end{array}$ \\
\hline $\begin{array}{l}\text { Process } \\
\text { Management }\end{array}$ & $\begin{array}{l}\text {-Product dan service design } \\
\text {-Process control } \\
\text {-Innovation dan continous } \\
\text { improvement of process, product } \\
\text { and services }\end{array}$ \\
\hline $\begin{array}{l}\text { Supplier } \\
\text { Management }\end{array}$ & $\begin{array}{l}\text {-Supplier quality } \\
\text {-Supplier involvement } \\
\text {-Supplier relationships }\end{array}$ \\
\hline
\end{tabular}

Sumber : Sila Ismali (2006)

Bruce at al. (2007) melakukan studi literatur manajemen operasional dan menyajikan daftar dan kriteria yang dapat menjelaskan pengukuran praktek 
TQM yang diambil dari beberapa sumber seperti Saraph et al. (1989), Flynn et al. (1994), Ahire et al. (1996), serta Black and Porter (1996).

Dibawah ini disajikan tabel tentang pengukuran TQM menurut Bruce et al. (2007):

Tabel 2

Indikator TQM beserta Pengukurannya

\begin{tabular}{|c|c|}
\hline Indikator TQM & Pengukuran \\
\hline \multirow{4}{*}{ Supplier relationship } & Long-term relationship \\
\hline & Small number of supplier \\
\hline & Supplier are certified \\
\hline & Supplier involvement \\
\hline \multirow{3}{*}{ Customer involvement } & Seek customers 'input \\
\hline & Involve customers in design \\
\hline & Customers'feedback encouraged \\
\hline \multirow{2}{*}{ Training } & Employee training \\
\hline & Management training \\
\hline \multirow{5}{*}{ Top management commitment } & Effective communication \\
\hline & Adequate resources available \\
\hline & Clear goals identified \\
\hline & Managers serve as champions \\
\hline & Promotes quality tools usage \\
\hline \multirow{2}{*}{ Product design } & Product designs are reviewed \\
\hline & Customer requirements analyzed \\
\hline
\end{tabular}

Sumber : Bruce et al. (2007)

Penelitian Das et al. (2008) mengembangkan berbagai konstruk TQM dari penelitian terdahulu hingga menghasilkan sembilan konstruk 
pelaksanaan TQM yang sudah teruji validitas dan reliabilitasnya. Analisis hasil penelitian menunjukkan bahwa kesepuluh konstruk TQM dinyatakan valid dan reliabel. Konstruk TQM yang diuji Das et.,al (2008) terdiri dari (1) Komitmen manajemen puncak (2) Perbaikan berkelanjutan (3) Inovasi (4) Studi banding (5) Keterlibatan Karyawan (6) Pelatihan (7) Fokus kepada pelanggan (8) Manajemen kualitas pemasok (9) Insentif dan penghargaan.

\section{Daya Saing Perusahaan.}

Manufaktur dihadapkan pada lingkungan eksternal yang tidak pasti sebagai akibat dari perubahan harapan pelanggan, persaingan global, dan akselerasi teknologi (Huber, 1984). Studi yang dilakukan oleh Shama (1995) tentang teori manajemen transformasi telah diidentifikasikan bahwa beberapa faktor seperti strategi bersaing, strategi harga, pengenalan produk baru dan distribusi oleh perusahaan difungsikan sebagai praktek pergeseran strategi manajemen dari orientasi pasar bersifat umum menuju pasar berbasis ekonomi.

Para akademis dan praktisi setuju bahwa tekanan persaingan globalisasi berlangsung pada abad duapuluh satu (D'Souza, 2000). Bagi perusahaan bahwa kemampuan memproduksi sesuai dengan permintan pelanggan merupakan strategi penting untuk memperoleh keunggulan dalam melayani pesanan pelanggan dan meningkatkan posisi persaingan (Zhang, 2003). Daya saing berhubungan dengan kemampuan perusahaan untuk tumbuh dan berhasil dengan baik diantara beberapa perusahaan yang sejenis (Bruce, 2007).

\section{Pengukuran Daya Saing Perusahaan}

Pada mulanya Skiner (1969) menyarankan kepada manufaktur agar menggunakan kemampuannya seperti pembiayaan (Cost), kualitas dan waktu dioperasionalkan sebagai senjata bersaing (competitive weapon). Hayes dan Wheelwright (1984) telah mengidentifikasi lima komponen dimensi strategi 
daya saing perusahaan meliputi pembiayaan, quality, penyerahan (delivery) mencakup penyerahan produk tepat waktu (on-time delivery), kecepatan pengiriman dan variasi produk serta pengenalan produk baru. Studi yang dilakukan oleh Marucheck et. al. (1990) menemukan bahwa banyak perusahaan mempertimbangkan cost, quality, delivery dan fleksibility sebagai empat strategi keunggulan daya saing perusahaan. Temuan ini sama seperti studi yang dilakukan oleh Marucheck et al. (1990) bahwa banyak perusahaan mempertimbangkan cost, quality, delivery dan fleksibility sebagai empat strategi keunggulan daya saing perusahaan. Koufteros (1995) melengkapi pengukuran kemampuan daya saing perusahaan yang dapat diukur melalui cost, competitive pricing, premium pricing, value-to-customer quality, product mix flexibility, product innovation dan customer service. Wacker (1996) menyarankan kepada manufaktur yang berorientasi pada proses cukup melakukan lima dimensi strategi bersaing agar memperoleh keunggulan bersaing dan memperoleh pasar. Ward et al. (1998) yakin bahwa keunggulan daya saing perusahaan dapat digambarkan empat elemen dasar yakni cost, quality, delivery dan fleksibility. Bruce et al. (2007) menguji dan mengembangkan pernyatan Ward et al. (1998) pada 114 perusahaan di United States dan membuktikan bahwa instrument tersebut dinyatakan valid dan reliabel. Empat variabel beserta indikator daya saing perusahaan seperti pada tabel dibawah ini :

Tabel 3

Daya Saing dan Pengukurannya

\begin{tabular}{|c|l|}
\hline Daya Saing & \multicolumn{1}{|c|}{ Pengukuran } \\
\hline \multirow{4}{*}{ Cost } & Unit production cost \\
\cline { 2 - 2 } & Inventory level \\
\cline { 2 - 2 } & Capacity utilization \\
\cline { 2 - 2 } & Productivity \\
\hline
\end{tabular}




\begin{tabular}{|l|l|}
\hline \multirow{4}{*}{ Quality } & Waste \\
\cline { 2 - 2 } & Product performance \\
\cline { 2 - 2 } & Product durability \\
\cline { 2 - 2 } & Product reliability \\
\hline \multirow{4}{*}{ Delivery } & Delivery speed \\
\cline { 2 - 2 } & Delivery reliability \\
\cline { 2 - 2 } & On-time delivery \\
\hline \multirow{4}{*}{ Flexibility } & Technical innovation \\
\cline { 2 - 2 } & Customization \\
\cline { 2 - 2 } & Rapid capacity adjustment \\
\cline { 2 - 2 } & Product design time \\
\hline
\end{tabular}

Sumber : Ward et. al., (1998); Flynn et al.(1999); Ward dan

Duray (2000); Bruce et al. (2007)

- Pembiayaan (Cost).

Pembiayaan (Cost) merupakan dimensi daya saing yang umum (Hayes \& Wheel-Wright,1984) yang dapat direfleksikan melalui kemampuan perusahaan untuk memenuhi permintaan pelanggan dengan harga yang terjangkau (Chacko, 2001).

Pengenalan produk baru melalui upaya perubahan produk merupakan kemampuan perusahaan untuk mewujudkan permintaan (Hayes dan Wheelwright, 1984). Pembiayaan (cost) produk merupakan fungsi dari biaya tenaga kerja, bahan baku dan alokasi overhead. Sebagian besar perusahaan seharusnya memahami secara rasional terhadap biaya produksinya (D'Souza, 2000). Sebagian manager setuju bahwa pembiayaan (cost) menjadi arena persaingan untuk setiap perusahaan (D'Souza, 2000). Sebelumnya 
Olhager (1993) pernah mengatakan bahwa persaingan pada arena utama seperti quality dan daya tanggap (responsiveness) berbasis pada fleksibilitas dan kecepatan.

- Kualitas (Quality)

Keluasan pengukuran kualitas secara umum dapat diterima sebagai dimensi daya saing perusahaan (Broh, 1982) selama kualitas mampu memenuhi keinginan pelanggan dalam hal penyesuaian desain, kecocokan penggunaan produk, kepercayaan kualitas produk, kinerja produk, ketahanan produk, kemampuan layanan produk (serviceability) dan keindahan produk (aesthetics) (Garvin, 1987). Ditambahkan pula oleh Deming (2000) dan Peters (1998) bahwa perbaikan kualitas merupakan upaya strategi untuk memperoleh daya saing. Berkaitan dengan kualitas, studi yang dilakukan oleh Garvin (1984) menjelaskan bahwa dimensi kualitas terdiri dari performance, feature, reliability, conformance, durability, aesthetics dan perceive quality.

Banyak organisasi yang menyimpulkan bahwa manajemen kualitas yang efektif dapat meningkatkan kemampuan bersaing dan memperoleh keunggulan bersaing di pasar (Anderson et al. 1994). Kualitas produk dan jasa yang baik memungkinkan terwujudnya kepuasan pelanggan serta perusahaan akan memperoleh keunggulan bersaing (Buttle, 1996).

- Penyerahan (Delivery)

Hayes dan Wheelwright (1984) telah mengidentifikasi lima komponen dimensi strategi daya saing perusahaan meliputi pembiayaan, quality, penyerahan (delivery) mencakup penyerahan produk tepat waktu (on-time delivery), dan kecepatan pengiriman dan pengenalan produk baru. Ditambahkan pula pada aspek dimensi penyerahan seperti tepat waktu juga meliputi kecepatan penyerahan produk baru (Hill, 1989). Penyerahan (delivery) yang menunjukkan kemampuan tepat waktu dan terpercaya merupakan senjata daya saing (Chacko, 2001). 
- Fleksibilitas (flexsibility)

Para peneliti dan manager manufaktur berpendapat bahwa fleksibilitas adalah strategi perusahaan untuk mengatasi ketidakpastian (Gerwin,1993). Menurut ukuran waktu, Olhager (1993) membedakan fleksibilitas menjadi dua yakni orientasi jangka pendek dan jangka panjang. Dalam waktu jangka pendek, fleksibilitas diartikan sebagai kecakapan untuk beradaptasi terhadap perubahan kondisi dengan mempertimbagkan sumber-sumber yang tersedia. Dalam jangka panjang, fleksibilitas dapat diukur melalui kecakapan perusahaan untuk memperkenalkan produk baru, sumber-sumber dan metode yang baru. Pengertian fleksibilitas manufaktur oleh Watts et al. (1993) diartikan sebagai kecakapan perusahaan untuk melakukan perubahan lingkungan operasional internal dengan cepat dan ekonomis untuk merespon perubahan kondisi pasar.

Selain Gerwin, Upton (1994) mendefinisikan fleksibilitas adalah peningkatan variasi produk yang tersedia, memperbaiki kecakapan perusahaan untuk merespon dengan cepat dan mencapai kinerja yang baik. Variasi fleksibilitas secara umum juga mencakup pengembangan produk (Zhang, 2001). Demikian pula oleh Zhang et. al. (2003) disebutkan bahwa fleksibilitas adalah kecakapan organisasi untuk meningkatkan variasi harapan pelanggan tanpa biaya yang berlebihan, waktu, ganguan organisasi dan penurunan kinerja.

\section{Kepuasan Pelanggan.}

Hunt (1977) menjelaskan bahwa kepuasan secara konsisten dari waktu kewaktu merupakan evaluasi emosi. Swan et. al. (1980), mendefinikan kepuasan pelanggan sebagai evaluasi secara sadar menyangkut apakah kinerja produk relatif bagus atau jelek atau apakah produk bersangkutan cocok atau tidak cocok dengan tujuan pemakaiannya. Zethaml (1988), menggaris bawahi bahwa kualitas sebagai sumber kepuasan. Rust dan Oliver (1994) menegaskan 
pandangannya dan menyarankan bahwa kepuasan pelanggan menggambarkan derajat keyakinan pelanggan serta perasaan positip terhadap kepemilikan atau manfaat layanan yang mereka peroleh.

Kepuasan pelanggan adalah derajat yang dirasakan oleh pelanggan ketika menerima produk dan jasa melebihi dari pada harga yang mereka bayarkan (Tracey, 1996). Kepuasan adalah suatu keadan dimana kebutuhan, keinginan dan harapan pelanggan dapat terpenuhi melalui produk yang di konsumsi (Gaspersz,2002).

Berdasar pada studi tentang persepsi dan pengalaman para manager dalam hal menilai kepuasan pelanggan, Slack (1987) dan Swamidass dan Newell (1987) menyarankan bahwa kepuasan pelanggan dapat diukur melalui daya ingat pelanggan (customer retention), perbandingan nilai penawaran harga, kualitas, reputasi produk dan loyalitas pelanggan. Sirdeshmukh et al. (2002) mengembangkan dan menguji dimensi kepuasan pelanggan sebagai variabel bebas yang meliputi kemampuan operasional, kebaikan operasional, orientasi penyelesaian masalah oleh pekerja dan kebijakan manajemen dan daya tanggap.

Zhang et. al. (2003), mengukur kepuasan pelanggan berdasar persepsi manager yang terdiri dari enam item yaitu (1) Pelanggan tetap berbisnis dengan kami, (2) Pelanggan dipuaskan oleh penawaran harga dan nilai guna produk, (3) Pelanggan mempunyai anggapan bahwa produk yang diterima melebihi harga yang mereka bayar, (4) Pelanggan kami dipuaskan oleh kualitas produk, (5) Perusahaan kami memiliki reputasi produk yang baik,(6) Pelanggan loyal terhadap produk perusahaan.

Bruce et. al. (2007) mengukur kepuasan konsumen menjadi empat indikator yakni: (1) Number of customer compliments (jumlah pelanggan yang memberikan pujian), (2) Number of repeat customers (pelanggan lama yang melakukan pembelian kembali), (3) Customer retention rate (tingkat ingatan pelanggan), (4) Level of customer satisfaction (tingkat kepuasan pelanggan). 
Keuntungan pelanggan yang puas yaitu terbentuk daya ingat yang kuat bagi pelanggan (Fornell, 1992), promosi positip dari mulut ke mulut (Reichheld dan Sasser, 1990) dan keuntungan finansial perusahaan yang melayani mereka (Fornell et al. 1995).

\section{Keterkaitan TQM dan Kepuasan Pelanggan.}

Deming (1982) menyarankan bahwa kepuasan konsumen merupakan hasil yang paling penting dari praktek TQM. Selama kepuasan pelanggan dapat mempengaruhi kinerja keuangan perusahaan seperti peningkatan market share dan keuntungan, maka kepuasan pelanggan akan menjadi elemen penting (Babich, 1992). Beberapa perusahaan yang menjalankan praktek TQM mencoba memotivasi karyawannya untuk aktif terlibat untuk mencapai kepuasan pelanggan, misalnya melakukan evaluasi kinerja karyawan tentang perhatian mereka terhadap pelanggan perusahaan (customer care) (Wilkinson et al.1993). Berdasarkan fakta-fakta bahwa TQM akan meningkatkan kualitas dan produktifitas sepanjang terjadi peningkatan kepuasan konsumen dan kepuasan pekerja (Baker dan Cagwin, 2000). Kesuksesan TQM tergantung dari bagaimana kesediaan organisasi untuk berubah dan menggunakan customer satisfaction sebagai ukuran untuk menuju sukses pada tingkat keputusan dan tindakan (Madu dan Kuei, 1993). Selain itu, Brah et al. (2002), menambahkan bahwa kesuksesan perusahaan tergantung dari bagaimana perusahaan dapat memuaskan kebutuhan dasar kosumen secara berkelanjutan. Perusahaan yang sudah melakukan orientasi pada pelanggan, kebanyakan mereka mendapat tantangan untuk melakukan pengukuran dan pengendalian terhadap harapan, kepuasan dan pengalaman pelanggan (Sebastianelli dan Tamimi, 2002). Oleh karenanya, kepuasan pelanggan merupakan konstruksi penting dan juga merupakan salah satu tujuan perusahaan (Li et. al. 2006). Ditekankan oleh Bruce et. al. (2007) bahwa TQM fokus pada pengembangan organisasi yang efektif dan tanggap terhadap kebutuhan pelanggan (customer needs). 
Beberapa studi yang menjelaskan hubungan antara TQM dan Kepuasan pelanggan kebanyakan menyatakan terdapat hubungan yang positip, seperti:

1. Anderson et al. (1994) pada studinya juga menemukan bahwa praktek TQM mendorong kepuasan pelanggan.

2. Forza dan Filippini (1998) menyatakan pada penelitiannya bahwa praktek TQM mempunyai pengaruh positip terhadap kepuasan pelanggan. Pada waktu yang bertepatan ditemukan bahwa indikator pengiriman (delivery) berpengaruh signifikan terhadap praktek TQM

3. Suatu studi yang dilakukan Das et. al. (2000) melaporkan ada hubungan positip antara praktek TQM dan kinerja kepuasan pelanggan.

4. Studi penelitian yang dilakukan oleh Sun (2000) di Norwegia menguji hubungan antara TQM, sertifikasi ISO 9000 dan kinerja. Hasil penelitian Sun (2000) menunjukkan bahwa kriteria TQM meliputi leadership, human resource development dan quality information memberikan kontribusi terhadap peningkatan kepuasan pelanggan (customer satisfaction).

5. Studi penelitian yang dilakukan oleh Terziovski (2006) menemukan bahwa ketika praktek manajemen kualitas dilakukan secara simultan mempunyai pengaruh positip dan signifikan terhadap pengembangan produktivitas dan kepuasan pelanggan.

Beberapa peneliti diatas kebanyakan mendukung bahwa praktek TQM berpengaruh positip terhadap kepuasan pelanggan, namun studi dilakukan oleh Bruce et al. (2007) menunjukkan bahwa praktek TQM tidak memberikan pengaruh positip terhadap kepuasan pelanggan, hal ini disebabkan bahwa kepuasan konsumen selama ini masih belum dapat meningkatkan kinerja keuangannya. Disamping itu temuan Bruce et. al. ( 2007), menyimpulkan bahwa selama TQM masih belum menjadi daya saing perusahaan, maka TQM tidak berpengaruh langsung terhadap kepuasan pelanggan.

Hasil studi literatur Mehra (2008) menunjukkan perbedaan dengan temuan Bruce et.al (2007). Studi Mehra (2008) terhadap sejumlah literatur 
tentang TQM dan kepuasan pelanggan menyatakan bahwa kebanyakan praktek TQM dapat meningkatkan kepuasan pelanggan. Oleh karenanya untuk memenuhi kepentingan bisnis, sebaiknya perusahaan beralih fokus kepada kepuasan pelanggan (Mehra dan Ranganathan, 2008). Harapan pelanggan dapat dipenuhi melalui perbaikan kualitas yang berkelanjutan. Pelanggan memiliki harapan terhadap organisasi jika harapan mereka tidak dapat dipenuhi perusahaan maka mereka menjadi tidak puas dan melakukan tindakan berhenti sebagai pelanggan (Mehra dan Ranganathan, 2008). Disimpulkan pula oleh Mehra dan Ranganathan (2008), bahwa TQM adalah merupakan strategi manajemen yang diadopsi untuk meningkatkan kepuasan pelanggan melalui konsentrasi kepada pelanggan.

Rujukan teoritis dan praktis diatas menjelaskan keterkaitan antara praktek TQM terhadap kepuasan pelanggan, maka dapat di-hipotesiskan :

H1 : Praktek TQM berpengaruh signifikan terhadap kepuasan pelanggan

\section{Keterkaitan TQM dan Daya Saing Perusahaan.}

Deming (1986) menyarankan bahwa TQM dapat mewujudkan pencapaian organisasi yang efektif dengan total biaya minimal dengan cara lebih konsentrasi pada sejumlah supplier/pemasok, menyediakan kebutuhan pelatihan dan teknologi kepada anggota organisasi serta melakukan pengawasan terhadap kinerja karyawan untuk menekan tingkat kesulitan, seperti penurunan kualitas produk, biaya penundaan/kelambatan dan pengerjaan ulang (rework). Carter dan Narasimhan (1994) juga menyarankan bahwa TQM lebih ditekankan pada pengembangan proses, hal ini akan memberikan kontribusi terhadap peningkatan produktivitas melalui upaya pemanfaatan pekerja dan proses. Ditambahkan pula oleh Hendricks dan Singhal (1996) bahwa fokus TQM yakni meningkatkan daya saing perusahaan, terutama pengembangkan kinerja keuangan secara keseluruhan. 
Hasil penelitian Narasimhan dan Jayaram (1998) menemukan bahwa praktek TQM mendorong daya saing perusahaan melalui dimensi pengembangan daya saing seperti quality dan cost.

Ahmad dan Schoeder (2002) menjelaskan hubungan antara TQM dan daya saing organisasi organisasi bahwa (1) Praktek TQM tidak hanya meningkatkan kualitas produk saja tetapi dapat mengurangi scrap), rework dan menjaga persediaan untuk menstabilkan proses produksi yang pada gilirannya akan meminimalkan biaya produksi (production cost) dan waktu,(2) Penurunan waktu memungkinkan perusahaan dapat meningkatkan kinerja penyerahan (delivery), (3) dan praktek TQM juga dapat membantu meningkatkan fleksibilitas, misalnya fleksibilitas tenaga kerja (workforce flexibility), dimana para pekerja dilatih pada berbagai keterampilan dan diberdayakan untuk mengambil keputusan, sehingga perusahaan dapat melakukan keputusan perubahan terhadap volume produksi tanpa berdampak negatip terhadap biaya produksi. Meningkatnya persaingan global, diperkuat dengan adanya deregulasi telah memotivasi organisasi untuk mengadopsi Total Quality Management (TQM) sebagai strategi untuk memenuhi kebutuhan konsumen. TQM merupakan filosofi manajemen untuk mencapai keunggulan bisnis dan sebagai daya saing organisasi melalui upaya pengembangan yang berkelanjutan sehingga praktek TQM dapat memberikan kontribusi terhadap daya saing organisasi (Chase et al 2006). Para manager melakukan praktek TQM sebagai upaya untuk menjalankan strategi perusahaan (Terziovski, 2006). Studi yang dilakukan oleh Bruce et al. (2007) menunjukkan bahwa para manager mengadobsi ISO 9000 sebagai cara untuk mencapai keunggulan daya saing melalui manajemen kualitas.

Hubungan TQM dan daya saing organisasi dapat diketahui dari hasil penelitian Bruce et. al. (2007) yang menemukan bahwa baik upaya sertifikasi ISO 9000 dan praktek TQM dapat meningkatkan daya saing perusahaan dan 
pada akhirnya akan mempengaruhi kepuasan pelanggan. Dengan demikian TQM memberikan kontribusi terhadap daya saing perusahaan.

Rujukan teoritis dan praktis diatas menjelaskan keterkaitan antara praktek TQM terhadap Daya saing perusahaan, maka dapat di-hipotesiskan :

H2 : Praktek TQM berpengaruh signifikan terhadap daya saing perusahaan.

\section{Keterkaitan Daya Saing Perusahaan dan Kepuasan Pelanggan.}

Daya saing berhubungan dengan kemampuan perusahaan untuk tumbuh dan berhasil dengan baik diantara beberapa perusahaan pada industri tertentu (Bruce et al. 2007). Banyak organisasi yang menyimpulkan bahwa manajemen kualitas yang efektif diantaranya dapat meningkatkan kemampuan bersaing dan memperoleh keunggulan daya saing di pasar (Anderson et al. 1994).Daya saing perusahaan yang baik ditandai dengan adanya peningkatan kualitas produk, penjualan, kepuasan pelanggan dan market share (Quazi dan Padibjo, 1998). Marucheck et al. (1990) menemukan bahwa banyak perusahaan mempertimbangkan cost, quality, delivery dan flexiibiliy sebagai empat strategi keunggulan daya saing bisnis. Pada perkembangannya, perusahaan melakukan empat ciri tingkatan yang dapat diidentifikasi yakni pemeriksaan, pengendalian kualitas, jaminan kualitas dan TQM untuk melakukan perbaikan kualitas (Van der Wiele et al. 1997). Ditambahkan oleh Karta (2004) bahwa upaya peningkatan produktivitas dan profitabilitas dapat dilakukan melalui perbaikan kualitas dengan biaya bersaing untuk dapat bertahan pada situasi persaingan. Adanya perilaku pelanggan yang mengharapkan perbaikan mutu dan meminta standar yang tinggi maka pada situasi terjadi persaingan mendorong perusahaan untuk tidak berdiam diri dan berusaha untuk meningkatkan kepuasan pelanggan (Fryer et al. 2007). Pengaruh antara daya saing perusahaan terhadap kepuasan pelanggan nampak pada penelitian Bruce et al. (2007) yang menguji hubungan antara pelaksanaan ISO 9000, praktek TQM, daya saing, kepuasan pelanggan 
dan kinerja bisnis. Hasil penelitian membuktikan adanya pengaruh daya saing perusahaan terhadap peningkatan kepuasan pelanggan.

Rujukan teoritis dan praktis diatas menjelaskan keterkaitan antara Daya saing perusahaan terhadap Kepuasan pelanggan, maka dapat di-hipotesiskan :

H3 : Daya saing perusahaan berpengaruh signifikan terhadap kepuasan pelanggan

\section{KESIMPULAN}

Merujuk pada pembahasan di atas, maka dapat dibentuk model kerangka penelitian yang menjelaskan hubungan antara variabel praktek TQM terhadap kepuasan pelanggan yang dimediasi oleh variabel daya saing perusahaan.

Adanya pemberlakuan perdagangan bebas CAFTA 2010 merupakan alasan untuk melakukan studi yang berhubungan dengan praktek TQM, daya saing perusahaan dan kepuasan pelanggan.

Sehingga model kerangka penelitian dapat digambarkan sebagai berikut : 


\section{Gambar 1. Usulan}

\section{Kerangka Model Penelitian}

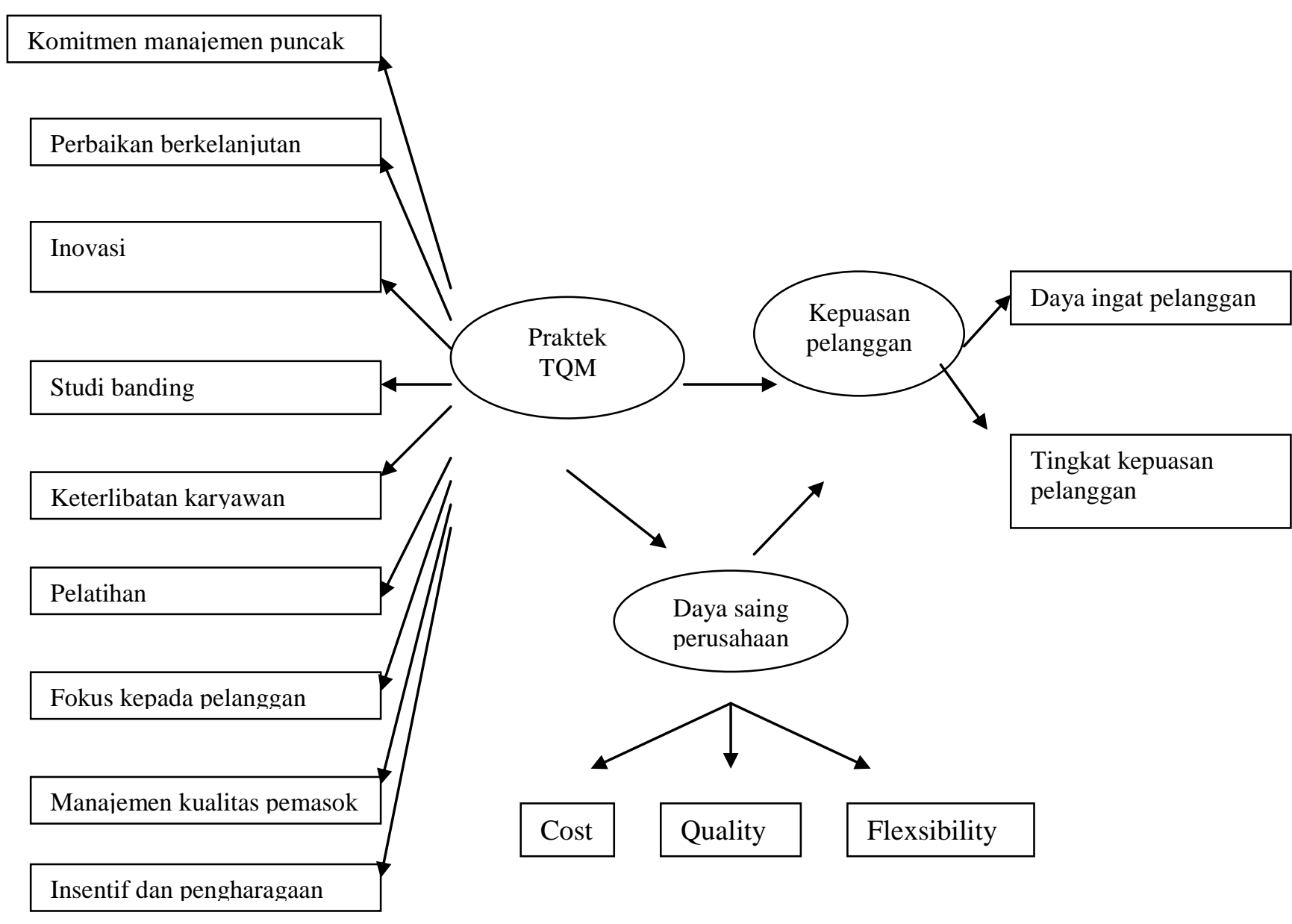

Gambar diatas ingin menguji dan menganalisis apakah ada pengaruh langsung dari variabel latent praktek TQM terhadap variabel latent kepuasan pelanggan dan ingin pula menguji apakah ada pengaruh tidak langsung dari variabel latent praktek TQM terhadap variabel latent kepuasan pelanggan yang dimediasi oleh variabel latent daya saing perusahaan.

Beberapa saran untuk tahapan usulan penelitian dapat dilakukan sebagai berikut : 
- Menetapkan terlebih dahulu beberapa indikator yang dapat merefleksikan variabel laten yang akan dibentuk, seperti variabel laten praktek TQM dapat direfleksikan oleh beberapa indikator seperti komitmen manajemen puncak, perbaikan berkelanjjutan, inovasi, studi banding, keterlibatan karyawan, pelatihan, fokus kepada pelanggan, manajemen kualitas pemasok serta insentif dan penghargaan

Variabel laten Daya Saing Perusahaan dapat direfleksikan oleh indikator seperti Cost, Quality dan Fleksibility. Variabel laten Kepuasan pelanggan dapat direfleksikan oleh indikator Daya Ingat Pelanggan dan Tingkat Kepuasan Pelanggan.

- Unit sampel penelitian yakni para manager yang bertanggung jawab dengan kualitas seperti manager operasional (General Manager), manager pabrik, manager kualitas, asurance manager atau adjustment manager. Penelitian dapat dilakukan di perusahaan manufaktur.

- Sebaiknya menggunakan kuesioner dengan skala Likert. Ketika data primer sudah terkumpul lakukan uji validitas dan reliabilitas kuesioner.

- Untuk memastikan apakah masing-masing ketiga variabel latent dapat membentuk satu faktor yang baik maka perlu dilakukan CFA (Conformatory Factor Analysis) terlebih dahulu. Bila masing-masing ketiga variabel latent tersebut dinyatakan layak membentuk sebuah faktor, untuk langkah selanjutnya dapat dilakukan analisis SEM (Structural Equation Modeling). Analisis SEM digunakan untuk menguji apakah model kerangka penelitian yang dibentuk sesuai dengan data primer yang dikumpulkan.

Dari hasil pengujian SEM maka akan diketahui hubungan dan pengaruh praktek TQM terhadap Kepuasan Pelanggan yang dimediasi oleh Daya Saing Perusahaan. 


\section{DAFTAR PUSTAKA}

Ahire, S.L., Golhar, D.Y., Waller, M.A. 1996. Development dan validation of TQM implememtation constructs. Decision Sciences 27(1), 3-56

Ahmad, S., Schroeder, R.G. 2002. The importance of recruitment dan selection process for sustainability of total quality management, The International Journal Quality and Relibility Management 19 (5), 540-551

Anderson, W.W., Fornell, C and D.R. Lehmann. (1994). Customer satisfaction, market share and profitability: Finding from Sweden. Journal of Marketing. 58.3:53-66.

Barker, KJ dan Cagwin, D. 2000. New evidence relating TQM to financial performance: an empirical study of manufacturing firms, faculty working paper, Ldaner University, Greenwood, SC.

Black, S.A., Porter, L.J. 1996. Identification of the critical factors of TQM, Decision Sciences 27 (1), 1-21

Bigne, Enrique. dan Blesa, Danreu. 2003. Market orientation, trust dan satisfaction in dyadic relationship: a manufacturer-retailer analysis, International Journal of Retail \& Distribution Management Vol. 31 Nou 11. pp. 574-590.

Broh, R., A.1982. Managing quality for higher profits. New York: McGraw-Hill

Bruce S., Han, Shaw K.Chen, Maling Ebrahimpour. 2007 The impact of ISO 9000 dan TQM dan Business performance, Journal of Business dan Economic Studies, Vo. 12 NO.2 
Buttle, F. 1996. AN investigation of willingness of UK certificated firms to recommend ISO 9000, International Journal of Quality Science 1 (2), 40-50.

Carter, R.J., Narasimhan, R. 1994. The role of purchasing dan materials management in total quality management dan customer satisfation. International Journal of Purchasing dan Materials Management 30 (3),3-15

Chacko, Thomas dan Wacker,John.G.2001. An examination of strategic goals dan management practices of Russian enterprises, International Business Review 10. 574-490.

Chase, R.B., Jacobs, F.R. \& N.J. Aquilano. 2006. Operations management for competitive advantage, 11 th edition. New York, New York: McGraw-Hill.

Crosby, P.B 1979, Quality is Free: The Art of Making Quality Certain, Hodder \& Stoughton, New York, NY.

Das, Anupam., Paul, Himangshu. Dan Swierczek, Fredric.W. 2008. Developing dan validating total quality management(TQM) constructs in the context of Thaildan's manufacturing industry, Bechmarking An International Journal, Vol.15 No.1 pp. 52-72

Deming, W.E.1986, Out of the Crisis, MIT Press, Cmbridge, MA

Deming, W.E.2000, Out of Crisis, Center for Advanced Engineering, MIT, Cambridge, MA.

Filippini, R.1997. Operation management research:some reflection in evolution, models dan empirical studies in OM, International Journal of Operations $\mathcal{E}$ Production Management, Vol. 17 No.7, pp. 655-70

Flynn, B.B., Schoeder, R. G. dan Sakakibara,S. 1994.A framework for quality maagement research dan an associated measurement instrument, Journal of Operation Management, Vol. 11.pp.339-66.

Fornell, C., Ittner, C.D. dan larcker, D.F. 1995, Understaning dan using the American customer satisfaction index (ACSI): assessing the financial impact of quality initiatives, paper presented at IMPRO 95, Juran Intitute's Conference on Managing for Total Quality. 
Forza, C. dan R. Filippi.1998. TQM impact on quality conformance dan customer satisfaction: A causal model, International Journal of Production Economics. 55.1:1-20

Fryer, K.J., Antony,J. dan Douglas,A. 2007. Critical success factors of continous improvement in the sector. A literature review dan some key findings, The TQM Magazine, Vol.19 No.5, pp. 497-517

Garvin, D.A. 1987. Competing on the eighth dimensions of quality. Havard Business Review 65 (6), 101-109.

Gaspersz, Vincent. 2002. Total quality management. PT Gramedia Pustaka Utama.,Jakarta

Gerwin, D., 1993. Manufacturing flexibility, a strategic perspective. Manage. Sci. 39 (4), 395-410.

Hayes, R.H., \& Wheelwright, S. C. 1984. Restoring our competitive edge: Competing through manufacturing. New York: Wiley.

Hill, T.J.1989. Manufacturing strategy: Text dan cases: Homewood,IL: Irwin.

Hunt, H.K. 1977. CS/D - overview dan futureresearch direction, in Hunt, H.K. (Ed.), Conceptualisation dan Measurement of Customer Satisfaction dan Dissatisfaction, Marketing Science Institute, Cambrige, MA, pp. 92-119.

Ishikawa, K. 1976. Guide to Quality Control, Asian Productivity Organization, Tokyo.

Juran, M.J.1986. Quality Progress, August, pp.14-24

Kartha, C.P.2004. A comparison of ISO 9000:2000 quality system stdanards, QS 9000, ISO/TS 16949 dan Baldrige criteria, The TQM Magazine, Vol.16 No.5, pp. 331-40

Koufteros, X.A., 1995. Time-Based Competition: Developing a Nomological Network of Construct dan Instrument Development. Unpublished Dissertation. The University of Toledo, Toledo, $\mathrm{OH}$. 
Li, B., Riley, M.W., Lin, B dan E.Qi. 2006. A comparison study of customer satisfaction between the UPS dan FedEx. Industial Management dan Data Systems.106.2:182-199

Madu, C.N., Kuei, C.H., 1993. Introducing strategic quality management, Long Range Planning 26 (6),121-130.

Marucheck, A., Pannesi, R. dan C. Danerson. 1990. AN exploratory study of the manufacturing strategy process in practice, Journal of Operations Management .9.1:101-123.

Mehra S., dan Ranganathan S. 2008. Implementing total quality management with a focus on enhancing customer satisfaction, International Journal of Quality E Reliability Management Vo.25. No.9, pp. 913-927

Mehra, S., Hoffman. J. M. dan Sirias, D.2001. TQM as a management strategy for the next millennia, International Journal of Operations dan Production Management, Vo. 21 No. 5/6, pp. 855-76

Narasimhan, R.dan J. Jayaram. 1998. Causal lingkages in supply chain management: An exploratory study of North American manufacturing firms, Decision Sciences 29.3:579-605

Olhanger,J. 1993. Manufacturing flexibility dan profitability, Int.J. Prod. Econ. 30-31, 67-78.

Peters, T. 1998. Facing up to the need for a management revolution, California Management Review, Vol.30 No.2,pp. 8-38

Quazi, H.A. dan Padibjo, S.R. 1998. A jouney toward total quality management through ISO 9000 certification: a study on small dan medium-sized enterprice in Singapore, International Journal of Quality $\mathcal{E}$ Reliability Management, Vol.15 No.5,pp. 364-71

Reichheld, F. F. dan Sasser, W. 1990. Zero defection: quality comes to services, Havard Business Review, September/October, pp. 105-11 
Rust, R, dan Oliver, R.1994. Service quality: Insight dan managerial implication from the frontier, in Rust, R. dan Oliver, R. (Eds), Service Quality: New Directions in Theory dan Practice, Sage, New York, NY,pp. 1-19

Saraph, J.V. Benson, P.G dan R.G. Schroeder. 1989. An instrument for measuring the critical factors of quality management, Decision Sciences. 20. $4: 810-829$

Sebastianelli,R.,Tamimi,N. 2002 How product quality dimensions relate to defining quality, The International Journal of Quality dan Reliability Management 19 (4),442-454

Shama, A. 1995. Developing dan testing theory of management transformation from planned to market economy: The case of Russia.Technological Forecasting dan Social Change, 48, 77-100.

Sila, Ismail. 2006. Examining the effect of contextual factors on TQM dan performance through the lens of organizational theories: An empirical study, Journal of Operations Management 25. 83-109

Sirdeshmukh, D., Singh, J. dan Sabol, B. 2002. Consumer trust, value, dan loyalty in relational exchanges, Journal of Marketing, Vol. 66, pp. 15-37.

Skinner, W. 1969. Manufacturing - missing link in corporate strategy, Havard Business Review, 136-145

Slack, N. 1987. The flexibility of manufacturing systems, International Journal of Operations dan Production Management 7 (4), 35-45.

Sun, H. 2000. Total quality management, ISO 9000 certification dan performance improvement, International Journal of Quality $\mathcal{E}$ Reliability Management, Vol.17 No.2, pp.168-79

Swan, J.E dan M.R Bower. 1998. Service Quality dan Satisfaction: The Process of People Doing Thing Together, Journal of Service Marketing, Vol 12, No.1 pp 59-72 
Terziovski, Mile. 2006. Quality management practices dan their relationship with customer satisfaction dan productivity improvement, Management Research News.Vol 29. No.7 pp 414-424

Upton, D.M. 1994. The management of manufacturing flexibility, California Management Review. Winter, 72-89.

Van der Wiele, A., Dale, B.G. dan Williams,A.R.T.1997,ISO 9000 series registration to taotal quality management: the transformation journey, International Journal of Quality Science, Vol.2.No.4, pp. 236-52.

Wacker, J. G. 1996. A theoretical model of manufacturing lead times dan their relationship to a manufacturing goal hierarchy, Decision Sciences 27 (3), 484-517.

Ward, P.T., McCreery, J.K. Ritzman, L. P. dan D. Sharma. 1998. Competitive Priorities in operations management, Decision Sciences.29.4:1035-1046

Warta Ekonomi. 2010. "Facebooknomics" bangkitnya bisnis 2010 via jejaring sosial. Majalah.Tahun XXI. 28 Desember-10 Januari 2010

Watts, C., Hahn, C., Sohn, B. 1993. Manufacturing flexibility: concept dan measurement, Operational Management. Rev. 9 (4), 33-44

Wilkinson, A.,A.,Redman,T.,Snape,E.,E. 1993. Quality management and Manager: An Institute of Management Report. Corby Institute of Management.

Zeithaml, V.A. 1988. Consumer perceptions of price, quality dan value a means: a means-end model dan synthesis of evidence, Journal of Marketing, Vol. 52 No.3,pp. 2-22.

Zhang, Qing yu., Vonderembse,Mark A.,Lim,Jeen-Su, 2003. Manufacturing flexibility: defining dan analyzing relationship among competence, capability, dan customer satisfaction, Journal Operations Management 21, 173-191 
Zhang, Q. 2001. Technology infusion enabled value chain flexibility: a learning dan capability-based perspective. Unpublished dissertation. The University of Toledo, Toledo, $\mathrm{OH}$. 